\title{
Design and Implementation of FS-I Method to Improve Effectiveness of Product Advertising using Social Media, Based on Quality Function Deployment and Fuzzy Servqual
}

\author{
Nenny Sulestiyowati ${ }^{*}$, $R$. Rizal Isnanto ${ }^{2}$, Adian Fatchur Rochim ${ }^{3}$ \\ ${ }^{1}$ Master of Information System, Post-graduate School, Diponegoro University, Semarang, Indonesia \\ 2,3 Department of Computer Engineering, Faculty of Engineering, Diponegoro University, Tembalang, \\ Semarang, Indonesia, 50275
}

\begin{abstract}
The development of advertising, many companies use social media as an alternative online advertising. It is more interactive to promote their product. The purpose of study is to determine the comparison of strategies to improve the quality of advertising services on several social media. The results of the validity and reliability test showed that the items of questions for the questionnaire were all valid and reliable. The method used in this study is fuzzy servqual and quality function deployment. The fuzzy logic integration aims to calculate the total weight, average, and gap values of the subjectivity of the results of the servqual method. The proposed improvement in this research is based on data processing using the quality function deployment method. The main target of the proposed improvement by making the most popular company advertisements, providing up-to-date information, lots of promotions, the most interesting features, and many customer interests.
\end{abstract}

Keywords. quality function deployment, effectiveness, advertising, social media

\section{Introduction}

The rapid development of technology makes changes in all aspects of life, especially in changes in the way humans consume information. An alternative attempt to marketing a product or service using the Internet and be more interactive can use social media (SocMed). Currently, online media have sprung up on social networks such as Twitter, Line, Instagram and corporate websites that are used for marketing [1]. The platform that refers to the use of social networking sites on mobile devices advertising for a company's products and brands is referred to as mobile social media advertising [2]. Marketing strategies using SocMed increase sales widely with relatively low costs. The availabilities of data in SocMeds are used

* Corresponding author: nennysulestiyowati@gmail.com 
by marketers to open markets digitally. Identification customer perceptions using data in the SocMed for marketing purposes, has a risk. The perceived risk of customers and the benefits of using the SocMed have something to do with the relationship and convenience of customers with marketers who are publicly available social media [3]. Customers find it easier to find product information that will be purchased because they do not need to go to the sales location. In line with the growth of the Internet and various companies promoting their product through their websites, and then advertise it through the SocMed [4]. The SocMed is a tool to access information, especially customers and other users, to help the innovation process and company performance.

However, this research uses limited variety of social media data [5]. Customers find it easier to find product information that will be purchased through social media with notifications. Choi, in 2018 concluded that the insight of a new theory of the emergence of added value to the company's prestige that advertising on social media will increase effectiveness in different markets [6]. SocMeds that are often used public to market, and sell products needs an evaluation tool for the effectiveness of the use of SocMed in corporate advertising. From various SocMeds advertisements like Instagram, Line, Twitter has different segmentation.

This research proposes a method to evaluate SocMed as an advertising tool to promote of products. Based on the changes, the expected outcome is the effective value of each SocMed. The proposed method used Quality Function Deployment method and the Fuzzy Servqual approach. The proposed method namely FS-I method. The choice of fuzzy method because several strategic objectives of activities to assess the effectiveness of advertising on social media. The fuzzy calculation structure is integrated with measuring and improving services to build a system of advertising effectiveness on social media [7]. The fuzzy logic integration aims to calculate the total weight, average, and gap values of the subjectivity of the results of the Servqual method. The proposed improvement in this research is based on data processing using the quality function deployment method. It, shows technical responses of the main target in FS-I method by making the most popular company advertisements, providing upto-date information, lots of promotions, the most interesting features, and many customer interests.

First section explain introduction and previous research, second section describes materials and method, third section describes implementation of the validity test and reliable test of respondent, four section describes result and discussion explain priority and target goal, and finally section conclude SocMed ranking based on the smallest negative gap value.

\section{Materials and Methods}

\subsection{Materials}

Using advertising and SocMed research can be described as the objectives, strategies, attractiveness, and tactics of corporate advertising on social media [8]. Targeting techniques is a successful way for advertisers to increase the effectiveness of advertisements, but also have weaknesses such as lack of innovation in developing a promotion [9]. The results of these studies indicate the company's customer response to get negative or positive information. Therefore, marketers can influence customer perception, and ultimately the value of the effectiveness of advertising on social media can be measured. This shows the importance of considering aspects of the media environment when developing advertising [10].

The questions were prepared using the service quality criteria proposed in Servqual. To paper were using to this paper quality dimensions: 
- Tangible - The ability of a company's brand to display promotional media that are attractive.

- Reliability - expectations regarding display, timeliness of providing information.

- Responsiveness - provides information through rapid media or responsiveness.

- Assurance - provide attractive promotions to customers accurate and specifically.

- Empathy - knowledge provided through social media, to grow customer trust.

The gap assessment was tested on 40 questionnaire respondents. Source of research data is to identify customers [11]. And then, giving 15 questionnaire questions to one customer. Some question categories have counts 5 questions for advertising on Instagram, 5 questions for advertising on Line, and 5 questions for advertising on Twitter. Data is collected in the middle of May 2020 come to a restaurant location, and then ask customers who are at the restaurant to answer the questionnaire is available on google form, by inputting customer self-data, and answer some questions that are already available.

Validity and reliability tests were performed. Validity test is done to find a correlation between the customer vote on the questionnaire with the total score. If the T-table value is 1.68 , while the T-calculated coefficient value more than 1.68 , it can be concluded the statement item is valid.

$$
T_{\text {count }}=\frac{r_{x y \sqrt{n-2}}}{\sqrt{\left(1-r_{x y^{2}}\right.}}
$$

Reliability test used Cronbach's alpha. A variable can be said to be reliable if the value of Cronbach's alpha is greater than 0.6 value [12].

$$
r=\left(\frac{k}{k-1}\right)\left(1-\frac{\sum \sigma b^{2}}{\sigma t^{2}}\right)
$$

Questionnaires were distributed by determining the criteria weights for questions based on the servqual dimension approach Table 1 . The weight of the quality criteria is assessed using a three-digit Likert scale, can be indicated in Table 2.

\begin{tabular}{|c|c|c|c|}
\hline No & Dimension & Code Attribute & Information \\
\hline \multirow{3}{*}{1} & \multirow{3}{*}{ tangible } & a1 & Questions tangible for Instagram \\
\hline & & a2 & Questions tangible for Line \\
\hline & & a3 & Questions tangible for Twitter \\
\hline \multirow{3}{*}{2} & \multirow{3}{*}{ reliability } & b1 & Questions reliability for Instagram \\
\hline & & b2 & Questions reliability for Line \\
\hline & & $\mathrm{b} 3$ & Questions reliability for Twitter \\
\hline \multirow{3}{*}{3} & \multirow{3}{*}{ responsiveness } & $\mathrm{c} 1$ & Questions responsiveness for Instagram \\
\hline & & $\mathrm{c} 2$ & Questions responsiveness for Line \\
\hline & & c3 & Questions responsiveness for Twitter \\
\hline \multirow{3}{*}{4} & \multirow{3}{*}{ Assurance } & $\mathrm{d} 1$ & Questions assurance for Instagram \\
\hline & & $\mathrm{d} 2$ & Questions assurance for Line \\
\hline & & $\mathrm{d} 3$ & Questions assurance for Twitter \\
\hline \multirow{3}{*}{5} & \multirow{3}{*}{ Empathy } & e1 & Questions empathy for Instagram \\
\hline & & e2 & Questions empathy for Line \\
\hline & & e3 & Questions empathy for Twitter \\
\hline
\end{tabular}

Table 1. The Code Attribute 
Table 2. The questions Attribute

\begin{tabular}{cl}
$\begin{array}{c}\text { Code } \\
\text { Attribute }\end{array}$ & \multicolumn{1}{c}{ The Questions Attribute } \\
\hline a1 & A serving advertising for products on Instagram is very interesting \\
\hline b1 & The most recent Instagram advertising platform \\
\hline c1 & Upload of product on Instagram are always up to date \\
\hline d1 & A very many discount promo deals on Instagram \\
\hline e1 & Information products on Instagram is interested in customers \\
\hline a2 & A serving advertising for products on Line is very interesting \\
\hline b2 & The most recent Line advertising platform \\
\hline c2 & Upload of product on Line are always up to date \\
\hline d2 & A very many discount promo deals on Line \\
\hline e2 & Information products on Line is interested in customers \\
\hline a3 & A serving advertising for products on Twitter is very interesting \\
\hline b3 & The most recent Twitter advertising platform \\
\hline c3 & Upload of product on Twitter are always up to date \\
\hline d3 & A very many discount promo deals on Twitter \\
\hline e3 & Information products on Twitter is interested in customers \\
\hline
\end{tabular}

Table 3. Likert Scale

\begin{tabular}{ccccc}
\hline Number & Perception & value & Expectation & value \\
\hline 1 & Good & 3 & High & 3 \\
\hline 2 & Medium & 2 & Medium & 2 \\
\hline 3 & Bad & 1 & Low & 1 \\
\hline
\end{tabular}

\subsection{Methods}

Fuzzy logic provides a means of presenting uncertainty and is an excellent tool for modelling. Fuzzy provides a simple way to draw definitive conclusions from ambiguous, or inaccurate information [13]. This research uses a combination of Fuzzy and Quality Function Deployment method to recommend the effectiveness of advertising from three SocMeds. Figure 1 shows the combination of the method.

\section{Combination of Fuzzy Logic and Quality Function Deployment}

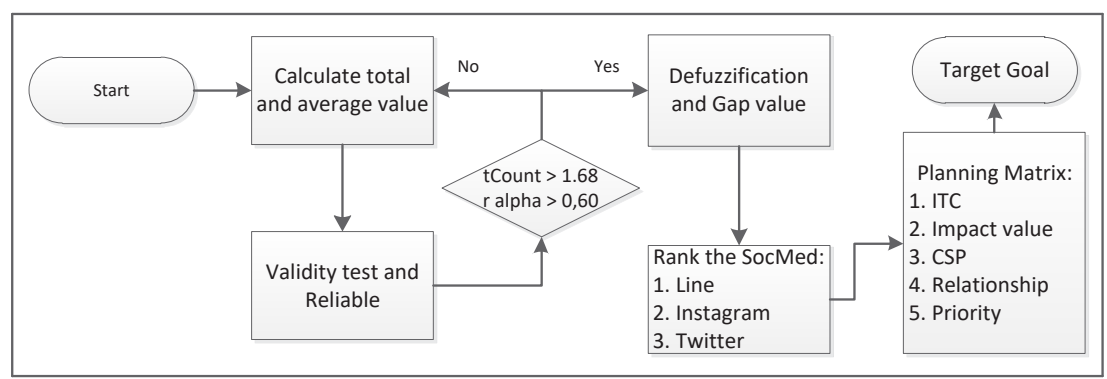

Figure 1. Framework of the stage method 
Step 1 : Calculate of the total value and average value of respondents.

The first step is to each value given by the respondent on the questionnaire in each attribute will be calculated totally and calculating the average.

Step 2: Defuzzification value is calculated which is the process of returning the value to a firm or real value.

$$
\text { Defuzzification }=\frac{1}{6}(a+4 b+c)
$$

After getting the defuzzification value for the level of perception and defuzzification for the level of expectation, the gap for each attribute can be calculated.

$$
\text { Gap }=\text { perception }- \text { expectation }
$$

Step 3 : Rank the SocMeds alternatives from calculate gap value.

Step 4 : Collection of planning matrix [14].

After data is determined about the attributes of complications, then prepared planning matrix containing about important information.

- Importance to costumer (ITC)

This column contains information about the level of importance of each customer's voting needs

- Impact value

$\begin{array}{ccc}\text { symbol } & \text { Impact value } & \text { information } \\ 0 & 3 & \text { strong } \\ \triangle & 2 & \text { less } \\ \text { empty } & 1 & \text { weak } \\ & 0 & \text { nothing }\end{array}$

- Customer satisfaction performer (CSP)

This column contains customer perceptions about the attractiveness of an advertisement promo on SocMed.

- Relationship

$$
\mathrm{CSP}=\frac{\sum \text { Attribute value }}{\sum \text { Number of Responden }}
$$

The result of multiplying the impact value with the ITC of each customer. The calculation formula is as:

\section{Relationship = impact value $\mathrm{x}$ ITC}

- Priority, is the value that will be the highest and lowest priority scale

Step 5 : Target value stage.

The target or proposed improvement to be achieved from the calculated analysis results.

- Goal

Target value of satisfaction to be achieved for the product being developed. The specified goal value is able to improve the quality of advertising services or make the quality of advertising services better.

Target Goal Value:

goal

information

priority $\geq 4$ if it reaches the target, there will be an increase in effectiveness

$2<$ priority $<4$ if it reaches the target, there will be an increase in effectiveness but not large 
priority $\leq 2$ if it reaches the target, there is no increase in effectiveness

\section{Implementation}

The implementation in the validity test, if $t$-count $>\mathrm{t}$-table then the item is declared valid. Based on the value of the product moment with $n=40$ at the $5 \%$ significance level obtained t-table $=1.68$. Table 4,5 and 6 show the results of the validity test of the customer questionnaire on SocMeds.

Table 4. Validity test on Instagram

\begin{tabular}{lccccc}
\hline \multirow{2}{*}{ Validity test } & \multicolumn{5}{c}{ tTable 5\% N $=40 ;$ tCount $>$ tTable } \\
\cline { 2 - 6 } & a1 & b1 & c1 & d1 & e1 \\
\cline { 2 - 6 } & 0,46 & 0,66 & 0,59 & 0,33 & 0,53 \\
\hline rxy & 3,21 & 5,44 & 4,61 & 2,2 & 3,86 \\
\hline tCount & 1,68 & 1,68 & 1,68 & 1,68 & 1,68 \\
\hline tTable & valid & valid & valid & valid & valid \\
\hline Valid/Not & & & & & \\
\hline
\end{tabular}

Table 5. Validity test on Line

\begin{tabular}{|c|c|c|c|c|c|}
\hline \multirow{3}{*}{ Validity test } & \multicolumn{5}{|c|}{ LINE } \\
\hline & \multicolumn{5}{|c|}{ tTable $5 \% \mathrm{~N}=40 ;$ tCount $>$ tTable } \\
\hline & $\mathrm{a} 2$ & $\mathrm{~b} 2$ & $\mathrm{c} 2$ & $\mathrm{~d} 2$ & $\mathrm{e} 2$ \\
\hline rxy & 0,62 & 0,62 & 0,47 & 0,52 & 0,28 \\
\hline tCount & 4,92 & 5,02 & 3,35 & 3,78 & 1,82 \\
\hline tTable & 1,68 & 1,68 & 1,68 & 1,68 & 1,68 \\
\hline Valid/Not & valid & valid & valid & valid & valid \\
\hline
\end{tabular}

Table 6. Validity test on Twitter

\begin{tabular}{|c|c|c|c|c|c|}
\hline \multirow{3}{*}{ Validity test } & \multicolumn{5}{|c|}{ TWITTER } \\
\hline & \multicolumn{5}{|c|}{ tTable $5 \% \mathrm{~N}=40 ;$ tCount $>$ tTable } \\
\hline & a3 & b3 & $\mathrm{c} 3$ & $\mathrm{~d} 3$ & e3 \\
\hline rxy & 0,56 & 0,35 & 0,41 & 0,26 & 0,63 \\
\hline tCount & 4,21 & 2,37 & 2,78 & 1,75 & 5,06 \\
\hline tTable & 1,68 & 1,68 & 1,68 & 1,68 & 1,68 \\
\hline Valid/Not & valid & valid & valid & valid & valid \\
\hline
\end{tabular}

Information for valid and invalid is if the tCount is greater $(>)$ than the tTable can be said to be valid. And if the tCount is smaller $(<)$ than the tTable can be said to be invalid. The value limit for tTable is 1.68 because formula tTable in microsoft excel $=\operatorname{TINV}(2 * 0.05) ; 40)$. 
The implementation a variable is said to be reliable if it gives a Cronbach alpha value $>$ 0.6 . can be seen the number of variances is 5.77436 and the total variance is 20.7462 and the results obtained are 0.77321 , then the statement is said to be reliable in Table 7 .

Table 7. Reliable to code attribute

\begin{tabular}{|c|c|c|c|c|c|}
\hline Code Attribute & Rsp1 & Rsp2 & $\ldots n$ & Rsp40 & Item Variance \\
\hline a1 & 3 & 3 & $\ldots$ & 1 & 0,28 \\
\hline a2 & 3 & 2 & $\cdots$ & 1 & 0,30 \\
\hline a3 & 3 & 2 & $\ldots$ & 2 & 0,36 \\
\hline b1 & 3 & 3 & $\cdots$ & 3 & 0,20 \\
\hline $\mathrm{b} 2$ & 3 & 1 & $\cdots$ & 3 & 0,72 \\
\hline b3 & 3 & 2 & $\ldots$ & 2 & 0,30 \\
\hline $\mathrm{c} 1$ & 3 & 1 & $\cdots$ & 1 & 0,71 \\
\hline $\mathrm{c} 2$ & 3 & 1 & $\cdots$ & 2 & 0,40 \\
\hline $\mathrm{c} 3$ & 3 & 3 & $\cdots$ & 3 & 0,27 \\
\hline $\mathrm{d} 1$ & 3 & 3 & $\ldots$ & 3 & 0,21 \\
\hline $\mathrm{d} 2$ & 3 & 2 & $\ldots$ & 2 & 0,42 \\
\hline $\mathrm{d} 3$ & 3 & 3 & $\ldots$ & 2 & 0,23 \\
\hline e1 & 3 & 3 & $\cdots$ & 3 & 0,46 \\
\hline e2 & 2 & 2 & $\cdots$ & 2 & 0,35 \\
\hline e3 & 3 & 2 & $\cdots$ & 1 & 0,48 \\
\hline \multicolumn{5}{|c|}{ Number of Varians } & 5,77 \\
\hline \multicolumn{5}{|c|}{ Total Variance } & 20,74 \\
\hline \multicolumn{5}{|c|}{$\mathrm{r}$ if alpha $>0,60$} & 0,77 \\
\hline
\end{tabular}

\section{Result and Discussion}

The best ranking result on table 8 it can be seen that the smallest negative gap value is line. And the one with the largest negative gap value is Twitter. It can be said that customers prefer to see advertisement on line, and advertisement on Twitter are less interested in customers.

Table 8 show the results of discussions for the best social media selection by calculating the defuzzification value and the gap of each total respondent.

Table 8. Social media ranking from gap value

\begin{tabular}{lcccc}
\hline \multirow{2}{*}{ Social Media } & \multicolumn{2}{c}{ Defuzzification } & \multirow{2}{*}{ Ranking } & Gap \\
\cline { 2 - 3 } & Perception & Expectation & & \\
\hline LINE & 12 & 15 & 1 & -3 \\
\hline INSTAGRAM & 11,83 & 15 & 2 & $-3,16$ \\
\hline TWITTER & 11,67 & 15 & 3 & $-3,33$ \\
\hline
\end{tabular}

After accumulation of the best social media rankings, and then will be calculate the defuzzification and gap values in the question attribute in Table 9, the attributes (e1, e2, e3) 
empathy have the highest negative gap value of $-29,833$. Through the negative gap value on the empathy attribute it can be seen that only some information through advertisements is of interest to the customer. Attribute $(\mathrm{d} 1, \mathrm{~d} 2, \mathrm{~d} 3)$ assurance becomes the attribute that has the smallest negative gap value of -13.5 so it can be seen that many customers already know the discount information through advertisements.

Table 9. Attribute question ranking

\begin{tabular}{llcccc}
\hline \multirow{2}{*}{ Code attribute } & \multirow{2}{*}{ Attribute } & \multicolumn{2}{c}{ Defuzzification } & \multirow{2}{*}{ Ranking } & \multirow{2}{*}{ Gap } \\
\cline { 3 - 4 } & & Perception & Expectation & & \\
\hline (a1, a2, a3) & tangible & 103,5 & 120 & 2 & $-16,5$ \\
\hline (b1, b2, b3) & reliability & 97,16 & 120 & 3 & $-22,83$ \\
\hline (c1, c2, c3) & responsiveness & 93 & 120 & 4 & -27 \\
\hline$(\mathrm{d} 1, \mathrm{~d} 2, \mathrm{~d} 3)$ & assurance & 106,5 & 120 & 1 & $-13,5$ \\
\hline$(\mathrm{e} 1, \mathrm{e} 2, \mathrm{e} 3)$ & empathy & 90,16 & 120 & 5 & $-29,83$ \\
\hline
\end{tabular}

After calculating the ranking of attribute will be done a solution, proposed solution to the improvement of the effectiveness of advertising on social media is to calculate, relationship, priority, and target goal:

- Condition 1 for Line : table that shows the impact value in the form of symbols

Table 10. Social media as Line

\begin{tabular}{|c|c|c|c|c|c|c|c|c|}
\hline & \multirow{2}{*}{ LINE } & \multicolumn{5}{|c|}{ Expectation } & \multirow{2}{*}{ ITC } & \multirow{2}{*}{ CSP } \\
\hline & & $\mathrm{a} 2$ & $\mathrm{~b} 2$ & $\mathrm{c} 2$ & $\mathrm{~d} 2$ & $\mathrm{e} 2$ & & \\
\hline \multirow{7}{*}{ Perception } & a2 (tangible) & 0 & & & & & 4 & 2,72 \\
\hline & b2 (reliability) & & $\Delta$ & & & & 3 & 1,82 \\
\hline & c2 (responsiveness) & & & $\Delta$ & & & 2 & 2,27 \\
\hline & $\mathrm{d} 2$ (assurance) & & & & 0 & & 5 & 2,67 \\
\hline & e2 (empathy) & & & & & 0 & 1 & 2,8 \\
\hline & elationship & 12 & 3 & 2 & 10 & 3 & & \\
\hline & priority & 5 & 3 & 2 & 4 & 3 & & \\
\hline
\end{tabular}

- Condition 2 : Acceptable stability in decision making

The lowest ranking results on Line social media are attribute questions from the (c2) responsiveness that will be the result of proposed improvements on Line.

- Condition 1 for Instagram : table that shows the impact value in the form of symbols

Table 11. Social media as Instagram

\begin{tabular}{|c|c|c|c|c|c|c|c|c|}
\hline \multirow{2}{*}{\multicolumn{2}{|c|}{ INSTAGRAM }} & \multicolumn{5}{|c|}{ Expectation } & \multirow{2}{*}{ ITC } & \multirow{2}{*}{ CSP } \\
\hline & & a1 & b1 & $\mathrm{c} 1$ & d1 & $\mathrm{e} 1$ & & \\
\hline \multirow{5}{*}{ Perception } & al (tangible) & 0 & & & & & 4 & 2,65 \\
\hline & b1 (reliability) & & 0 & & & & 3 & 2,52 \\
\hline & $\mathrm{c} 1$ (responsiveness) & & & 0 & & & 2 & 2,3 \\
\hline & $\mathrm{d} 1$ (assurance) & & & & 0 & & 5 & 2,72 \\
\hline & $\mathrm{e} 1$ (empathy) & & & & & $\Delta$ & 1 & 2,12 \\
\hline \multicolumn{2}{|c|}{ Relationship } & 8 & 6 & 4 & 15 & 1 & & \\
\hline
\end{tabular}




$\begin{array}{llllll}\text { priority } & 4 & 3 & 2 & 5 & 1\end{array}$

- Condition 2 : Acceptable stability in decision making

The lowest ranking results on Instagram social media are attribute questions from the (e1) empathy that will be the result of proposed improvements on Instagram.

- Condition 1 for Twitter : table that shows the impact value in the form of symbols

Table 12. Social media as Twitter

\begin{tabular}{|c|c|c|c|c|c|c|c|c|}
\hline \multirow{2}{*}{\multicolumn{2}{|c|}{ TWITTER }} & \multicolumn{5}{|c|}{ Expectation } & \multirow{2}{*}{ ITC } & \multirow{2}{*}{ CSP } \\
\hline & & a3 & b3 & $\mathrm{c} 3$ & $\mathrm{~d} 3$ & e3 & & \\
\hline \multirow{5}{*}{ Perception } & a3 (tangible) & $\Delta$ & & & & & 4 & 2,2 \\
\hline & b3 (reliability) & & 0 & & & & 3 & 2,65 \\
\hline & c3 (responsiveness) & & & 0 & & & 2 & 2,47 \\
\hline & $\mathrm{d} 3$ (assurance) & & & & $\triangle$ & & 5 & 2,55 \\
\hline & e3 (empathy) & & & & & 0 & 1 & 2,15 \\
\hline \multicolumn{2}{|r|}{ Relationship } & 4 & 9 & 6 & 5 & 2 & & \\
\hline \multicolumn{2}{|r|}{ priority } & 2 & 5 & 4 & 3 & 1 & & \\
\hline
\end{tabular}

- Condition 2: Acceptable stability in decision making

The lowest ranking results on Twitter social media are attribute questions from the (e3) empathy that will be the result of proposed improvements on Twitter.

\section{Conclusions}

The results of the analysis by the fuzzy servqual method show that the attributes are the main priority in influencing the effectiveness of advertising strategies on social media. To improve the quality function deployment method for the analysis the proposed method use specified targets of SocMeds.

Planning the effectiveness of advertising strategies on SocMed is implemented into advertising features that can attract the attention of customers, can make customers want to follow up on social media, must be always excellent at providing information every day, giving very attractive discounts, and making social media advertisements become posts that are always waiting for customers.

The results show that the Line SocMed application has the lowest negative gap value of -3. It can be concluded that the Line application is the most effective compared than the Instagram and Twitter. Negative gap value of the Instagram is -3.17 and then the Twitter is the higher than others with the gap value of -3.33 .

\section{References}

1. Yadav, M., \& Rahman, Z. (2017). Telematics and Informatics Measuring consumer perception of social media marketing activities in e-commerce industry: Scale development and validation. Telematics and Informatics. https://doi.org/10.1016/j.tele.2017.06.001

2. Tan, G. W., Lee, V., Hew, J., and Ooi, K. (2018). The interactive mobile social media advertising: The imminent approach to advertise tourism products and services? Telematics and Informatics. https://doi.org/10.1016/j.tele.2018.09.005

3. Jacobson, J., Gruzd, A., and Hernández-garcía, Á. (2019). Journal of Retailing and 
Consumer Services Social media marketing: Who is watching the watchers? (September 2018). https://doi.org/10.1016/j.jretconser.2019.03.001

4. Ha, S., Huang, R., and Park, J. (2019). Journal of Retailing and Consumer Services Persuasive brand messages in social media: A mental imagery processing perspective. Journal of Retailing and Consumer Services, 48(January), 41-49. https://doi.org/10.1016/j.jretconser.2019.01.006

5. Corral, G., Zubielqui, D., Fryges, H., and Jones, J. (2017). Technological Forecasting \& Social Change Social media, open innovation and HRM: Implications for performance. (March 2016). https://doi.org/10.1016/j.techfore.2017.07.014

6. Choi, Y. K., Seo, Y., Wagner, U., and Yoon, S. (2018). Matching luxury brand appeals with attitude functions on social media across cultures 2 . Journal of Business Research, (September), 0-1. https://doi.org/10.1016/j.jbusres.2018.10.003

7. Sano, Natsuki, Kimura, Fuminori (2017). ScienceDirect Estimation of Customer Questionnaire

8. Juntunen, M., Ismagilova, E., and Oikarinen, E. (2019). B2B brands on Twitter : Engaging users with a varying combination of social media content objectives, strategies, and tactics. Industrial Marketing Management, (March), 0-1. https://doi.org/10.1016/j.indmarman.2019.03.001

9. Jung, A. (2017). Computers in Human Behavior The influence of perceived ad relevance on social media advertising: An empirical examination of a mediating role of privacy concern. Computers in Human Behavior, 70, 303-309. https://doi.org/10.1016/j.chb.2017.01.008

10. Rademaker, C. A., Royne, M. B., and Wahlund, R. (2015). Eco-harmful media perceptions and consumer response to advertising. Journal of Cleaner Production, 108, 799-807. https://doi.org/10.1016/j.jclepro.2015.08.071

11. Guan, Xie Lishan, Xinhua Huan, and Tzung-cheng (2019). Journal of Hospitality and Tourism Management A case study of hotel frontline employees. Journal of Hospitality and Tourism Management 39. 76 - 86

12. Chen, Liang-hsuan, and Ko Wen-chang (2009). Fuzzy approaches to quality fuction deployment for new product design. Fuzzy Sets and Systems 160. 2620 - 2639

13. Howells, K., and Ertugan, A. (2018). ScienceDirect ScienceDirect Applying fuzzy logic for sentiment analysis of social media network data in marketing. Procedia Computer Science, 120, 664-670. https://doi.org/10.1016/j.procs.2017.11.293

14. Sularto, Lana, Yunitasari Tristyanti (2015). User Requirements Analysis for Restaurant POS and Accounting Application Using Quality Function Deployment. Social and Behavioral Sciences 169. 266 - 280 